\title{
Narrowing the gap: access to HIV treatments in developing countries. A pharmaceutical company's perspective
}

James Cochrane Glaxo Wellcome plc, Greenford, UK

\begin{abstract}
The advent of new antiretroviral medicines means that the effects of HIV can now be curbed, but only one in twenty infected people have so far benefited. For those living in developing countries, the new treatments are practically unattainable. Governments, UNAIDS and pharmaceutical companies recognise this only too well and have rethought established assumption in order to try and overcome the challenges posed by cost, inadequate health services and unreliable local supply of medicines.

(Fournal of Medical Ethics 2000;26:47-50)
\end{abstract}

Keywords: AIDS; treatment gap; developing countries; Glaxo Wellcome; access to medicines; public health

The late 1990s have brought qualified hope to people living with the human immunodeficiency virus (HIV) for the first time since the epidemic began. Treatments that curb the devastating effects of the virus have reached clinics and hospitals, significantly cutting the number of AIDS deaths and, according to some estimates, reducing the overall costs of AIDS care. ${ }^{1}$ No one suggests that these treatments, based on sequential combinations of multiple antiretroviral drugs, can cure HIV infection. Rather they can, with careful use, keep people out of hospital and free to live and work independently for long periods.

But only one in every twenty of the estimated 33 million people infected with the virus worldwide ${ }^{2}$ has so far been able to benefit. Ninety-five per cent of HIV-positive people live in developing countries, where combination therapy with the new antiretroviral drugs is practically unattainable, and for many, even basic treatments for the opportunistic infections and symptoms of AIDS - such as aspirin and morphine - are hard to find. The picture is worst in Sub-Saharan Africa - home to 80 per cent of all of those who died of AIDS and 70 per cent of all those who were newly infected with HIV in 1998. In Uganda, for example, where two million people are estimated to be infected, officials of the Joint UN Programme on HIV/ AIDS (UNAIDS) believe that no more than 1,000 people have access to antiretrovirals. In South Africa, where some three million people are infected, no more than 2,000 people are thought to be receiving these drugs. Put simply, the countries with the greatest need for the drugs are also those least likely to have them.

To many, it may seem that the advent of the new treatments has simply widened the gap between rich and poor countries - and the fate of people with HIV in each. For years, public health officials and others have argued that the best way to overcome the HIV epidemic is to prevent the spread of the virus. Many valuable initiatives, from vaccine development to community-based programmes of education, are aiming to do exactly that. But the virus continues to spread, infecting an estimated 16,000 people every day. For them, talk of prevention comes too late. Treatment is all that is left.

Governments and UNAIDS have recognised this. They recognise that they bear some responsibility for narrowing the gap between those who can afford treatment and those who cannot. Equally, the pharmaceutical industry has taken steps to work with the public sector and widen access to its products without harming its own legitimate interests. Not for the first time, the AIDS pandemic has forced all those that it affects to rethink their assumptions and their practice. This article describes some of the key challenges that public and private sectors alike face in narrowing the "treatment gap" - and the first moves towards overcoming those challenges.

The cost of antiretroviral drugs is, of course, one obvious barrier to their wider use. In this context, my industry points out that the price of our products is heavily influenced by their research and development costs of $\$ 350-500$ million a product. It can take ten years to bring a drug from the laboratory bench to the market ${ }^{3}$ and the attrition rate during the process is still very high. 
A dozen antiretroviral drugs have appeared on the market since the beginning of the epidemic almost two decades ago. They have resulted from unprecedented productivity, generated by intense industry investment in new HIV therapies, together with governments' decisions to speed up the normal regulatory and approvals processes in response to AIDS. However, the medicines developed have generally been beyond the reach of people in low-income and middle-income countries. Treatment with a combination of three antiretroviral drugs, now seen as the "gold standard" in the West, costs around $\$ 30$ a day at US wholesale prices; treatment with two antivirals costs around $\$ 17$ a day. In many countries in Sub-Saharan Africa, governments spend as little as $\$ 6$ a person on health care in a whole year, and other equally pressing health problems jostle for their share of resources.

Cost, however, is not the only barrier. First, many people who are thought to be infected with HIV in Sub-Saharan Africa may not even be aware of the fact. Services for voluntary HIV testing and counselling are provided only patchily, and many individuals do not have access to them. In any case, people whose prospects of receiving treatment are poor have few incentives to take a test if all that the result will buy them is stigma and social rejection.

\section{Regular monitoring}

Second, antiretroviral therapy only works safely and well if it is conducted properly. If patients cease taking antiretrovirals, their health is likely to deteriorate as the HIV in their blood rebounds. In addition, they are also more likely to harbour drug-resistant strains of the virus that may then be transmitted to others and prejudice future treatment. So treatment must be supported by a set of services that includes regular monitoring to observe patients' levels of the immune system's CD4 $\mathrm{T}$ cells that HIV attacks, measurements of the levels of virus in the blood, and vigilance for resistant strains. Medical records must be properly maintained and accessible. Health workers themselves must be trained in specialist skills and must be able to counsel and support patients and explain to them why they must stick rigorously to the drug regimen. Finally, drug supplies must be reliable, and ordered regularly through a system that is not vulnerable to cash-flow problems. In many cases in low-income countries, these structures are simply not there: for example, medical records may be kept only on pieces of paper at patients' homes, and money paid to a hospital pharmacy may be used to repair an x-ray machine rather than to buy new drugs.
But these obstacles are no ethical justification for denying people in poorer countries the right to treatment. So UNAIDS, the pharmaceutical industry and national governments have begun some initiatives which, they hope, will increase the equity of antiretroviral treatment and bring basic drugs to many more of those who need them. It is too early at present to gauge how effective such responses can be, or what consequences they might have. None of the players can claim to have all of the answers to the extraordinary challenges posed by AIDS. In any case, health officials and non-governmental organisations know that the drugs are in circulation in some of the poorer countries, bought by individuals at Western prices or on the black market. Unmonitored and without proper counselling and testing, these treatments will be less than efficacious.

There are two new initiatives. The first aims to provide HIV-positive pregnant women with access, at reduced price, to short-course treatment with antiretrovirals to cut the risk of transmitting HIV to their babies. In 1994, research in the United States showed that antiretroviral therapy given during pregnancy, birth and to the newborn infant could reduce the risk of HIV transmission by two-thirds, ${ }^{4}$ but the cost and complexity of the regimens, $\$ 1,000$ for a course in the United States, put it beyond the reach of poorer countries. A study in Thailand, published early last year, showed that the risk could be halved when treated with AZT 300mg, given twice a day at or around week 36 of pregnancy up to birth in a non-breast-feeding population, at a cost of around $\$ 200$ at Western prices. Despite the obvious value of preventing infections with such a short treatment course, the outlay required to offer it to all pregnant women none the less denied it to most governments.

\section{Important results}

Last year, therefore, Glaxo Wellcome announced that it would enable governments in low-income countries and international agencies to buy Retrovir for up to 75 per cent less than the typical Western price, for use in short-course treatment intended to prevent mother-to-child transmission. Two trials in breast-feeding populations in Africa, CDC Ivory Coast and the ANRS 049 have shown that short course $\mathrm{ZDV}$ regimens given to mothers from week 36 to 38 and during labour, and in the case of ANRS 049 for one week postpartum reduces the risk of vertical transmission by $37-38 \%$ respectively. ${ }^{5}{ }^{6}$ Comparable results were obtained with Boehringer Ingelheim's nevirapine given as a single dose to mothers at the onset of labour and to the infants at 72 hours of birth or 
time of discharge. ${ }^{7}$ The Joint UN Programme on HIV/AIDS co-ordinated a multinational trial, known as PETRA, within Africa to determine the efficacy of combined ZDV/3TC on preventing vertical transmission of HIV. The early results from PETRA, announced at the Sixth Annual Conference on Retroviruses and Opportunistic Infections in Chicago on 1 February 1999 , demonstrated that despite breast-feeding, commencement of treatment during labour only followed by one week's treatment of both mother and infant, could reduce transmission of HIV by $37 \% .^{8}$ An increased reduction in transmission of $50 \%$ was obtained when treatment was initiated at 38 weeks of gestation. ${ }^{9}$ This result is important because of the widespread practice of breastfeeding in Africa. A study in Kenya has demonstrated that 32 per cent of HIV infection of newborns is attributable to breast-feeding for duration of up to 15 months. ${ }^{10}$ In view of the early PETRA results, Glaxo Wellcome has pledged similar reduced pricing for $3 \mathrm{TC}$ and Combivir (the fixed-dose combination of AZT and 3TC) to support this shorter regimen for pregnant women.

A key question is whether babies of HIVpositive mothers will continue to be protected if they are breast-fed after treatment stops - the realistic situation in most African countries. Earlier studies suggest that a substantial proportion of breast-fed babies are infected after the age of six months (personal communication, February 1999: Leroy V, epidemiologist, INSERM Unit 330, Victor Segalen University of Bordeaux 2, France). ${ }^{11}$ Long term analysis of the CDC Ivory Coast study in breast-fed populations shows that postnatal transmission of HIV at more than three months is similar in treatment and placebo groups. But more long term data are needed before researchers can be confident that the protection continues after this.

\section{Unanswered questions}

Glaxo Wellcome's decision to offer drugs at a lower price to poorer countries marks a break with usual practice. The industry has usually argued that patients in rich countries might resist effectively subsidising patients in poorer parts of the world and insist on equal terms. But because the burden of AIDS weighs so disproportionately heavily upon Africa decision makers readily reached a consensus that an innovative approach to pricing was needed.

We looked at the pricing of the drugs in the context of what the World Bank and the World Health Organisation (WHO) recommend to be costeffective health interventions. These can broadly be defined as any treatments, vaccines or other tools that buy a year of healthy life (a disability-adjusted life year, or DALY $)^{12}$ for less than the price of the country's average income per head. ${ }^{13}$ Glaxo Wellcome concluded that its reduced prices are well within these ranges. Nevertheless, industry officials recognise that there is no guarantee that governments will consider they can afford to buy the drugs in the long term.

There are other unanswered questions. What happens to women when they stop taking the therapy? Researchers have raised the theoretical possibility that levels of HIV in their bodies might rebound, as can happen in long term therapy. If this were true, it might endanger their health and that of any breast-fed infant by increasing the viral load in the breast milk. So far, the short term evidence does not support these fears ${ }^{11}$ but only longer term studies now under way will tell whether they are real or not.

Equally, and not surprisingly, some HIVpositive women in African countries object to the assumption that only their unborn child is worthy of publicly funded treatment. Why not long term therapy for the women themselves? The industry will always seek to reach the most ethical solution to such problems, but it does not pretend to have the answers or to offer the drugs for free. It looks to its partners in the public sector to find both political will and resources to ensure that long term care can be supported. At the same time, the industry is hopeful that it will be able to reduce the real cost of antiretroviral treatment in future.

The second initiative is equally a small step, but a profoundly important one. It comprises four pilot studies, in Chile, Cote d'Ivoire, Uganda and Vietnam, and aims to identify and overcome some of the obstacles blocking access to care among people with HIV/AIDS in resource-poor countries. It is concerned not only with new anti-HIV drugs but also with patented drugs for the prevention and treatment of opportunistic infections, other sexually transmitted diseases, and other AIDS-related illnesses

A number of industry partners, including Glaxo Wellcome, Hoffman-La Roche and Virco, have joined forces with UNAIDS and the national governments for this project. In each case, the national government must define clearly what the objectives of treatment are, how many people should be involved and who they should be, using transparent criteria, such as the individual's clinical stage of HIV disease, to determine whether or not he or she should be eligible. The government must also demonstrate that it can provide, through designated centres, all the elements of a proper treatment programme, including monitoring for resistance, counselling, and laboratory 
testing of viral load and CD4 T cell numbers. For its part, the industry partners are subsidising some of the necessary infrastructure costs, including reduced prices for the drugs.

\section{First step}

The Joint UN Programme on HIV/AIDS sees this project as a first step towards more widely accessible antiretroviral treatment. But the agency sees it as far more than that, too. For it, one of the biggest reasons for the project is the need to improve more basic treatments for people with HIV/AIDS, by bringing a regular supply of much needed drugs for preventing and treating opportunistic infections, and for palliative care, to all. Equally importantly, the initiative is seen as a way for governments in low-income countries to regulate the provision of antiretroviral drugs, and, it is hoped, to avert potentially disastrous misuse.

No one denies that the project is controversial At this stage, each of the four pilot studies will involve only a small number of people: what about the remainder in each country who are infected with HIV? What about the long term prospects that governments will sustain their commitment to buy the drugs? Are reduced prices any more affordable than full price with a health budget as small as those of many governments? So far, it is too early to say. But the prospects are better than before and the moves have stimulated wide interest. ${ }^{14}$ The steps may be small but at least they are narrowing the gap.

Fames Cochrane is Executive Director, Europe, the Middle East and Africa, Glaxo Wellcome plc, Greenford, Middlesex.

\section{References}

1 See, for example:McCollum, $M$, et al HAART reduces overall costs of HIV care at DVAMC-Denver. Fifth Conference on Retroviruses and Opportunistic Infections. February, 1998: abstract 200: 116 .
2 Joint United Nations Programme on HIV/AIDS (UNAIDS). AIDS Epidemic update: December 1998. Geneva: UNAIDS, 1998. (www.unaids.org/highband/document/epidemio/ wadr98e/pdf)

3 DiMasi JA. Success rates for new drugs entering clinical testing in the United States. Clinical Pharmacology and Therapeutics 1995;58:1-14, and: Office of Technology and Assessment. Pharmaceutical R\&D: costs, risks and rewards (OTA-H-523). Washington DC: US Government Printing Office, 1996.

4 Connor EM, Sperling RS, Gelber R, Kiselev P, Scott G, O'Sullivan MJ, et al. Reduction of maternal-infant transmission of human immunodeficiency virus type 1 with zidovudine of human immunodeficiency virus type 1 with zidovudine

5 Wiktor SZ, Ekpini E, Karon JM, Nkengasong J, Maurice C, Severin ST. Short-course oral zidovudine for prevention of mother-to-child transmission of HIV-1 in Abidjan, Cote d'Ivoire: a randomised trial. Lancet 1999; 353:781-5.

6 Dabis F, Msellati P, Meda N, Welffens-Ekra C, You B, Manigart O. Six-month efficacy, tolerance, and acceptability of a short regimen of oral zidovudine to reduce vertical transmission of HIV in breastfed children in Cote d'Ivoire and Burkino Faso: a double-blind placebo-controlled multicentre trial. Lancet 1999; 353:768-92

7 Guay LA, Musoke P, Fleming T, Bagenda D, Allen M, Nakabiito C. Intrapartum and neonatal single-dose nevirapine compared with zidovudine for prevention of mother-to-child transmission of HIV-1 in Kampala, Uganda.HIVNET 012 randomised trial. Lancet 1999;354:795-802.

8 Presentation to the Sixth Conference on Retroviruses and Opportunistic Infections, Chicago, USA, Jan-Feb 1999 reported in UNAIDS press release, 1999 Feb 1. Saba J, UNAIDS, Geneva. The Results of the PETRA intervention trial to prevent perinatal transmission in Sub-Saharan Africa (http: www.unaids.org/whatsnew/press/eng/mtet99e.html).

9 Saba J. Interim analysis of early efficacy of three short ZDV/3TC combination regimens to prevent mother-to-child transmission of HIV-1: the PETRA trial. Sixth Conference on Retroviruses and Opportunistic infections, Jan-Feb 1999; abstract S7.

10 Datta P, Embree JE, Kreiss JK, Ndinva-Achola JO, Braddick M, Temmerman M. Mother-to-child transmission of human immunodeficiency virus type 1 - report from the Nairobi study. Founal of infectious Diseases 1994;170:1134-40.

11 For data on late postnatal transmission see also Leroy V, et al. International multicentre pooled analysis of late postnatal mother-to-child transmission of HIV-1 infection. Lancet 1998 : 352:597-600

12 Murray CJLM, Lopez AD. The global burden of disease. Washington DC: Harvard University Press/WHO/World Bank, 1998.

13 World Bank. World development report 1993. Investing in health. Washington DC: World Bank,1993, and: World Health Organisation. Investing in health research and development. Report of the ad hoc committee on health research related to future intervention options. Geneva: World Health Organisation, 1996.

14 See, for example: Anonymous [editorial]. A positive response to perinatal HIV. Lancet 1999;353:511. 